\title{
An Overview on the Efficacy of Manual Therapy (Manipulations and Mobilisations) on Nonspecific Cervical Pain: A Systematic Review in Adults
}

\author{
José Antonio Mirallas Martínez \\ Head of Physical Medicine and Rehabilitation, Castellón General Hospital Castellón, \\ Spain
}

\section{Introduction}

Cervical pain is a common problem that is associated with significant morbidity and costs. We know relatively little about the effect of manual therapy on neck pain, and its efficacy remains unclear ${ }^{1}$. Manual therapy includes the following different forms of treatment:

1. "spinal manipulation", which is defined as low-amplitude, high-speed manual operations that are short, precise and selective for one vertebral segment; these manipulations are applied until the normal physiological range of motion is exceeded but without reaching the anatomical limit ${ }^{1}$;

2. "spinal mobilisation", which is defined as passive, low-speed movements of the vertebral segments within anatomical limits².

Manual therapy is applied primarily in cases of pain with a spinal origin, particularly nonspecific and mechanical pain, and it can be used either as a sole therapeutic option or in association with other types of drug treatment or physiotherapy ${ }^{3}$.

In this study, we evaluated meta-analyses and systematic reviews of randomised controlled trials (RCTs) because they represent the best scientific evidence in the hierarchy of evidencebased medicine (EBM).

\section{Objective}

The aim of this study was to assess the efficacy and safety of manual therapy (manipulation and mobilisation) for nonspecific cervical pain.

\section{Search strategy}

A search was conducted of the following electronic bibliographic databases from their respective starting dates to December 2010: Central Medline (March 2000), Embase (1947), Mantis (October 2008), Cinahl (May 2006), Icl (September 2008), Amed (December 2007), Pedro (November 1989), SciSearch (March 2005), the Cochrane Controlled Trials Register 
(April 1993), the Cochrane Musculoskeletal Review Group Specialised Trials Database (April 2004), and the Web of Science (1991).

A manual search was also conducted in the Journal of Manipulative and Physiological Therapeutics, Manual Therapy, Physiotherapy, Spine and Rehabilitation (Madrid). The following keywords were used: neck pain (cervicalgia), cervical spine (columna cervical), manual therapy (terapia manual), manipulation (manipulación), mobilisation (movilización), manipulation/mobilisation, and cervical manipulation versus mobilisation in adults. The first author of each study was used in subsequent searches to avoid missing relevant studies.

\section{Selection of studies}

We selected only meta-analyses and systematic reviews of RCTs that investigated the use of mobilisations and manipulations as treatments for nonspecific mechanical neck disorders. At least one of the following parameters was measured: pain, range of movement, pain on palpation, and overall or functional improvement. We excluded RCTs that analysed cervical pain with other aetiologies. The levels of evidence were classified in various ways by the authors $^{4}$, as shown in Table 1. The definition of RCT quality ranks the level of evidence as low, medium or high for scores below $25 \%$, between $25 \%$ and $50 \%$, and higher than $50 \%$, respectively, of the total maximum 5 .

1. Strong Evidence: Multiple high-quality RCTs.

2. Medium Evidence: One high-quality RCT or multiple low-quality RCTs.

3. Limited Evidence: One low-quality RCT.

4. Inconclusive Evidence: Inconsistent or contradictory results in multiple trials.

5. Absence of evidence: No studies.

$\mathrm{RCT}=$ randomised controlled trial.

Table 1. Levels of evidence ${ }^{4}$.

\section{Results}

The role of manual therapy in nonspecific mechanical cervical pain was determined by searching the literature and examining the results by year of publication.

Five low-quality RCTs were obtained from 1991 and earlier; therefore, it was not possible to draw conclusions, and further work to produce higher- quality studies is needed6.

From 1992 to 1996, 24 RCTs met the selection criteria; they were categorised by the type of intervention used (12, physical medicine; 9, manual therapy; 4, more than one form of intervention; 4, drug treatment; and 3, educational). We concluded that the various treatment techniques have not been studied in sufficient detail to properly allow for an assessment of their efficacy, and that the results were contradictory?

From 1997, we identified 14 RCTs totalling 892 patients. In these studies, we found the most explicit systematic reviews on the distinctions between mobilisations and manipulations and among acute, subacute and chronic pain. There were no RCTs on manipulation and only 3 low-quality RCTs on mobilisation (two of which dealt with cervical whiplash) ${ }^{8}$. 
From 1998 to 2002, 20 medium-quality RCTs were found; these RCTs showed better results for manual therapy and exercise (manipulation or mobilisation, manipulation and mobilisation or massage) than for the control groups (waiting list or placebo). There was no evidence that treatment by manipulation was better than the control 9 .

Among the 33 selected RCTs from 2003, 42\% ranked as high quality ${ }^{10}$. There was no evidence that treatment by manipulation was better than the control treatment ${ }^{11}$.

From 2004 to 2010, 12 RCTs met the selection criteria. Using the criteria developed by Koes et al. ${ }^{6}$ (and later adapted by Sarigiovannis and Hollins ${ }^{5}$ ), the RCTs had quality scores between 25 and 67 (out of a maximum of 100). Eight were medium-low quality, of which 6 reported positive results $12,13-17$ and 2 reported negative results 18,19 , and 4 were high quality, of which 2 reported positive results 2021 and 2 reported negative results $22^{*}, 23^{*}, 24$ ( $^{*}$ are from the same study; see Table 2). Thus, the evidence for the efficacy of manual cervical spine therapy remains inconclusive ${ }^{5}$. To evaluate the evidence for manual therapy, an analysis of the various processes yielded the following results.

\begin{tabular}{|c|c|c|}
\hline Study & Conclusion & $\begin{array}{l}\text { Score } \\
\text { (Scale: 0-100) }\end{array}$ \\
\hline Bronfort ${ }^{22^{*}}$ & Negative & 67 \\
\hline Evans ${ }^{23^{*}}$ & Negative & \\
\hline Hoving20 & Positive & 64 \\
\hline Hurwitz ${ }^{21}$ & Positive & 54 \\
\hline Yurkiw ${ }^{24}$ & Negative & 51 \\
\hline Wood $^{13}$ & Positive & 49 \\
\hline Pikula14 & Positive & 47 \\
\hline Jordan 18 & Negative & 44 \\
\hline Parkin-Smith ${ }^{15}$ & Positive & 41 \\
\hline Nordemar19 & Negative & 36 \\
\hline Modley 16 & Positive & 32 \\
\hline Vernon 12 & Positive & 29 \\
\hline Brodin $^{17}$ & Positive & 25 \\
\hline
\end{tabular}

*22 and 23 Both refer to the same study.

Positive: A statistically significant difference was observed in the efficacy of manual therapy (manipulation/mobilisation) and other treatments.

Negative: No statistically significant differences were observed in the efficacy of manual therapy or other treatments.

Table 2. The methodological scores of the RCTs ${ }^{4}$ according to the adopted criteria ${ }^{10}$.

\subsection{Acute neck pain}

There were no RCTs for the treatment of acute neck pain by vertebral manipulation ${ }^{25}$ (an absence of evidence) ${ }^{4}$. There were 3 low-quality RCTs for mobilisation ${ }^{25}$ (moderate evidence) ${ }^{4}$ and two for cervical whiplash ${ }^{26,27}$. In a randomised group of patients with acute neck pain (all of whom were previously treated with collars and analgesics), there were no differences among the mobilisation, TENS or control groups evaluated at 1, 6 and 12 
weeks $^{19}$. There was no evidence supporting the use of spinal manipulation ${ }^{25}$, and there was limited evidence against passive spinal mobilisation for acute neck pain ${ }^{25}$.

\subsection{Cervical whiplash}

For cervical whiplash, there were better pain reduction and mobility-recovery results at 8 weeks in the group treated with early active mobilisation than in those treated with conventional therapy (analgesics, advice and home exercise) ${ }^{26}$. There was less pain after 2 years with early active mobilisation compared with physiotherapy (cold or shortwave) or collars $^{27}$. There was moderate evidence in favour of early active mobilisation ${ }^{26,27}$ and no evidence supporting the use of spinal manipulation in whiplash ${ }^{25}$.

\subsection{Chronic subacute neck pain}

There were 2 RCTs $^{12,} 28$ (moderate evidence) ${ }^{4}$ comparing manual therapy with mobilisation or spinal manipulation 7,25 . No differences were observed in short-term pain and range of movement in patients with chronic neck pain who were randomised to treatment groups for manipulation or mobilisation ${ }^{28}$. This result differs from other studies that showed better short-term results with manipulation ${ }^{12}$. Thus, there is unclear evidence on the difference in the efficacy between manipulation and spinal mobilisation ${ }^{5,25}$.

Four RCTs $17,31,32,33$ (moderate evidence) ${ }^{4}$ compared manipulation and/or mobilisation with other treatments 25 . There was less pain in the patients treated with mobilisation and salicylates (compared with massage and salicylates or traction/electrical stimulation and salicylates) at 3 months, but not over the long term ${ }^{17}$.

There were better initial results with manual therapy (manipulation and mobilisation) than with physiotherapy (short wave, electrotherapy and ultrasound), conventional therapy (analgesics, home exercises and advice) or placebo, but there were no differences at 3 or 12 months ${ }^{31}$. Increased muscle relaxation was achieved by manipulation, but this effect was not significant ${ }^{31,32,33}$ (TE Global 0.42 ( $95 \%$ confidence interval, -0.005 to 0.85 ). Therefore, there is inconclusive evidence regarding the role of manual therapy (manipulation and mobilisation) in treating chronic neck pain ${ }^{5,25}$.

There was a better outcome in the manual therapy group (manipulation and/or mobilisation) than in the physical therapy and general medical treatment groups (analgesics, education and advice) at 7 and 26 weeks, but not after 1 year ${ }^{20,29}$. There was less pain, disability and drug consumption at 4 and 12 months after treatment, but with no differences between the treatment groups (physiotherapy and mobilisation, manipulation or intensive training) ${ }^{18,29}$. Mobilisation and strengthening exercises (isometrics with elastic bands) and mobilisation and resistance exercises (cephalic elevations in the prone and supine positions) produced better results than did the control treatment (recreational activity) in terms of reducing pain and increasing functional recovery after a year ${ }^{30}$.

When randomised to three treatment groups (i.e., manipulation (I), manipulation plus conventional exercise (II), or high-technology exercises, developed by MedX corporation, in addition to cervical extension isokinetic exercises (III)), no difference was observed among 
the groups at 3 months 22,29 . However, there was higher satisfaction at the end of 3 months in Group II 22,29, better results and higher satisfaction at 12 months in Groups II and III 22,29, better results at 24 months in Groups II and III 10,23 and higher satisfaction at 24 months in Group II10, 23 .

There was moderate short- and long-term evidence in favour of stretching programmes plus strengthening for chronic mechanical neck pain with or without headache ${ }^{29}$, and for stretching programmes for patients with chronic mechanical neck pain ${ }^{10}$. There was inconclusive evidence supporting the relative benefits of a programme of stretching plus strengthening exercises compared to manual therapy (mobilisation and manipulation) or to other therapeutic approaches $21,25,26,29$.

Studies or subcategories

(Note: Of the 960 eligible patients, only 336 agreed to participate.)

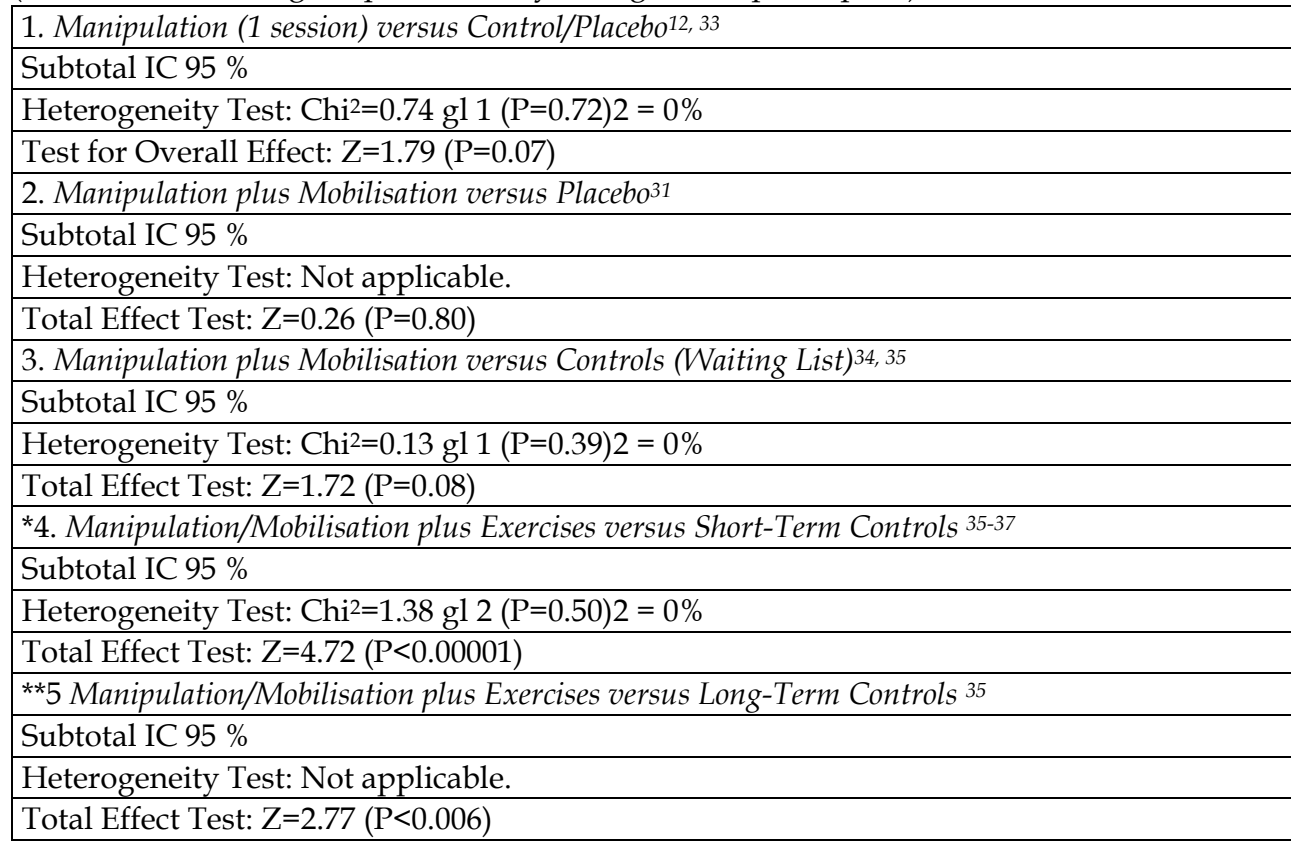

There was strong evidence against manipulation ${ }^{12,33}$ and manipulation plus mobilisation ${ }^{31,34,35}$ in isolation compared with controls (placebo/waiting list) for function and the general perceived effect in subacute or chronic mechanical neck disorders with or without headaches.

There was strong short-35-37* and long-term ${ }^{35 * *}$ evidence in favour of multimodal treatment (manipulation/mobilisation + exercise) compared with controls in subacute or chronic mechanical neck disorders with or without headaches for the following measures:

1) pain reduction [pooled SMD -0.85 (95\% CI: -1.20 to -0.50$)$ ];

2) improved function [pooled SMD -0.57 (95\% CI: -0.94 to -0.21)]; and

3) general perceived effect [pooled SMD -2.73 (95\% CI: -3.30 to -2.16)].

Table 3. External Validation 10 
There was inconclusive short- and long-term evidence on the effect of strengthening exercises for the relief of chronic mechanical neck pain ${ }^{10}$ and on the role of manual therapy in chronic neck pain 5, 10,25,29. There were no clear differences between exercises and manual techniques or other physical therapies, or between strengthening and resistance exercises 11 . It was thus not possible to determine which technique or dosage is most effective or whether certain groups benefit more from a given form of therapy 10,25 .

Regarding external validity, there have been comparative metaanalysis reviews of treatment by manipulation and mobilisation in mechanical neck disorders. These studies have used the resulting pain after treatment as a measure ${ }^{10,21}$, and the most significant data are shown in Table 3. These studies demonstrate that there is inconclusive evidence for the efficacy of manual therapy (manipulation and mobilisation) in chronic neck pain 5, 10, 25,28.

\subsection{Radiating neck pain}

There was greater improvement in function and pain with manual therapy (manipulation/mobilisation) directly on the cervical spine and indirectly on the shoulder and dorsal spine than without treatment ${ }^{37}$. We found limited evidence in favour of exercise and manual therapy (mobilisation/manipulation) in radiating chronic neck pain cases 9, 10, 25, 37. There was no evidence for the role of manual therapy (manipulation and mobilisation) in radicular cervical cases ${ }^{10}$. There was moderate evidence against stretching programmes plus strengthening for myofascial pain in the neck and shoulder $5,29,31$. Consequently, the evidence for the efficacy of manual therapy (manipulation and mobilisation) was inconclusive $5,29,31$.

\subsection{Cervicogenic headaches}

At both 7 weeks and after 1 year, the intensity and frequency of pain decreased more with manipulation, exercise, and manipulation with exercise than it did with no treatment 35 , and combining the treatments (manipulation and exercise) did not change the results ${ }^{35}$. There was strong short- and long-term evidence in favour of multimodal treatments that included exercise and mobilisations in subacute or chronic mechanical neck pain with headache, as assessed by pain reduction, improved function and general perceived effect ${ }^{29}$. There was moderate short- and long-term evidence in favour of strengthening exercises alone or with other treatments for pain, function and general perceived effect on chronic neck pain with headache ${ }^{35}$. There was also evidence against the efficacy of manipulation and/or mobilisation alone in the treatment of cervicogenic headaches ${ }^{10,11}$. Thus, there is inconclusive evidence regarding the efficacy of manual therapy (isolated manipulation and mobilisation) in the treatment of cervicogenic headaches ${ }^{10,11 .}$

\section{Safety}

Most sources indicated that the incidence of serious accidents during treatment by cervical spine manipulation is low (approximately 1 per million per year) ${ }^{1,3}$. The most commonly described injuries were Wallenberg's syndrome, dissection or thrombosis of the vertebral or carotid arteries and brainstem injury ${ }^{1}$. Adverse reactions were more likely to occur after manipulation than after cervical spinal mobilisation ${ }^{3}$. Therefore, iatrogenic sequelae may be 
reduced, outcomes may be improved, and satisfaction and security may be increased by using mobilisation ${ }^{1}$. Only one study reported adverse effects from manual therapy ${ }^{21}$.

Spinal manipulation and mobilisation are commonly used in the treatment of cervical spine disorders ${ }^{35}$. Their use has been associated with serious complications, including an increased incidence of cerebrovascular accidents (CVAs) ${ }^{39-42}$ and minor side effects, such as headache, stiffness, and symptom worsening ${ }^{43-45}$. In a systematic review of the adverse effects of spinal manipulation, Ernst ${ }^{41}$ suggested that spinal manipulation is associated with frequent mild and transient adverse effects, as well as more serious complications that can lead to permanent disability or death. The incidence of reported adverse effects has varied between studies (ranging, for example, between 1 per 50,000 manipulations ${ }^{44}$ and 1 per $\left.228,050^{43}, 46\right)$.

A review of the literature related to cervical artery dysfunction and manual therapy suggests that due to reporting bias, inferences about the magnitude of the risks of manipulative therapy should be conservative in relation to the surveys ${ }^{46}$. Other authors have also stated that due to concerns about the validity of the calculations applied to these data, it is not currently possible to estimate the risk of complications after treatment in a meaningful way without reporting the incidence of risk for cervical manipulation ${ }^{47}$.

Ernst concluded that incidence figures cannot be reliably estimated at present, due to the lack of sufficiently broad and rigorous prospective studies ${ }^{41}$. Thiel and Bolton have suggested the need for a system to record adverse effects on a routine basis that is not based on the practitioner's subjective recall ${ }^{48}$. Several tests also exist to gauge the risk of adverse effects, with and without the use of mobilisation or high-velocity thrust (HVT) techniques, which have not been as widely reported in the literature ${ }^{43}$.

Beca (2002) reported a higher incidence of minor adverse reactions with the use of non-HVT techniques $(27.5 \%)$ compared with HVT techniques (16.1\%). Magarey reported a higher rate of adverse effects associated with the use of non-HVT techniques ( 1 out of 180 therapists per week of treatment) compared with HVT techniques ( 1 out of 177.5 therapists per week of treatment) ${ }^{44}$. Magarey also reported that adverse effects were caused by the particular test procedures, which involved rotation. In contrast, Hurwitz reported that patients who received spinal manipulation were more likely to experience adverse effects than were patients treated with mobilisation; however, his risk estimates were imprecise. The reported side effects associated with mobilisation included increased pain, headache and fatigue ${ }^{49}$.

The use of functional testing of the position of the cervical spine has been proposed as part of the evaluation of vertebrobasilar insufficiency (VBI) before the application of HVT and nonHVT techniques to the cervical spine ${ }^{50}$. However, functional position tests have been criticised for their "lack of sensitivity, specificity ${ }^{51}$ and validity $42^{\prime}$. The poor validity of the functional position tests for the detection of alterations in blood flow has also been noted $52-54$.

It appears that the risk of adverse reactions is associated with the testing procedures themselves ${ }^{39}$ coupled with the time consumed by the testing ${ }^{44}$, suggesting that the clinical utility of functional position testing is questionable. However, these tests are currently defended for VBI assessment as part of a comprehensive assessment protocol that also includes a detailed subjective evaluation and places special emphasis on the therapists' clinical reasoning in the process ${ }^{50}$. 


\section{Discussion}

The definition and concept of manual therapy varies according to different authors. For example, the study with the highest-scoring methodology includes mobilisation of the spine and soft tissue through coordination and stabilisation exercises ${ }^{20}$. The wide variety of manipulative techniques used and the qualifications of the professionals involved make comparing studies difficult ${ }^{20}$. Virtually all authors have agreed on the need for high-quality and long-term RCTs to establish precisely the efficacy and safety of manual therapy ${ }^{1,2}$, thereby facilitating meta-analyses rather than only systematic reviews ${ }^{5}$. It is encouraging to note that the three papers with the highest scores for methodological quality were published after the year 200020,21,23. However, none of these RCTs included pre-randomisation, and only one included post-randomisation for psychosocial assessment of the patients ${ }^{21}$.

Additionally, the qualifications or professional experience of the manual therapist were not considered; these qualifications are important for the proper indication and application of cervical spinal manipulations ${ }^{5}$.

It would also be desirable to implement placebo treatments that are as similar as possible to manual therapy techniques but without any specific activity ${ }^{5}$. However, the absence of evidence for the efficacy of physical treatment does not mean that such treatments are not effective (according to evidence based medicine), although the evidence does suggest that manual spinal therapy has a definite placebo effect ${ }^{1,2}$.

There is a need for higher-quality and longer-term RCTs to demonstrate the efficacy and safety of manual therapy in general, and of its main techniques (manipulation and mobilisation) for mechanical cervical spine disorders in particular ${ }^{55}$. There should be a national notification system for adverse effects, applied on a routine basis, that utilises a protocol for collecting the adverse effects associated with the use of these techniques and the therapist's VBI assessment “ 56 “.

There is no evidence to suggest that physiotherapists are better qualified and are more effective in the application of cervical spinal manipulations than are other healthcare professionals“ $57^{\prime \prime}$.

The populations with neck pain, with or without headaches, in the RCTs were quite homogeneous.

Howe“32" reported a rapid and significant improvement of symptoms in patients with a painful or rigid neck, pain or paresthesia in the shoulder, or pain or paresthesia in the hand. The main weaknesses of this study include the following: im sub-optimal randomisation and a failure to mention drop-outs Bitterli“34” reported an improvement of $35 \%$ in the group receiving early active mobilisation, but found no improvement after spinal manipulation. This study has a high risk of bias due to the low quality of the methodological design (non-randomised trial, small sample).

Jull (2002) "35" reported a reduction of the frequency and intensity of headache and neck pain when using spinal manipulation, and the effect lasted until the 12-month follow-up. However, the inability to control the placebo effect could increase the risk of bias (see Tables 4,5 , and 6). 


\begin{tabular}{|c|c|c|c|}
\hline 营 & 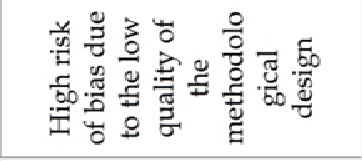 & ' & 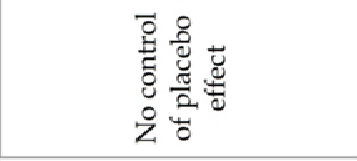 \\
\hline 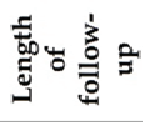 & $\approx \frac{n}{\frac{n}{2}}$ & 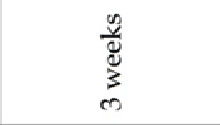 & 궈 $\stackrel{\text { 异 }}{\stackrel{0}{\Xi}}$ \\
\hline 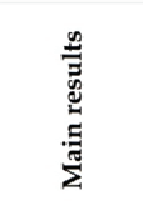 & 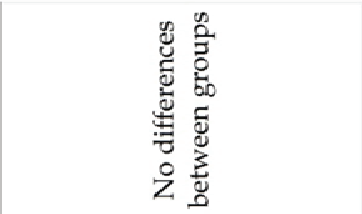 & 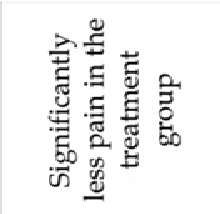 & 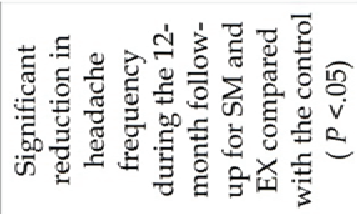 \\
\hline 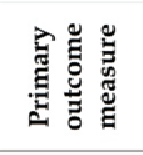 & 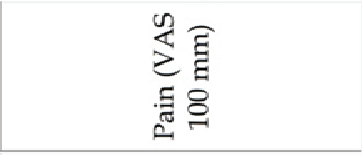 & ๘ & 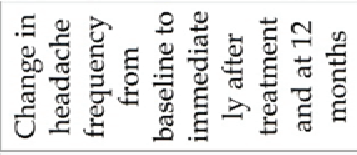 \\
\hline 옳 & 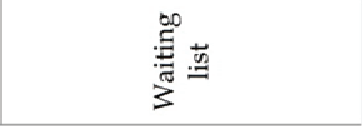 & 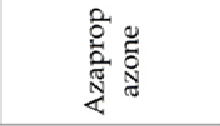 & 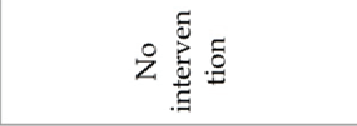 \\
\hline 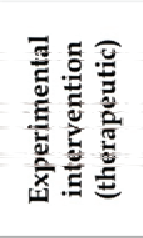 & 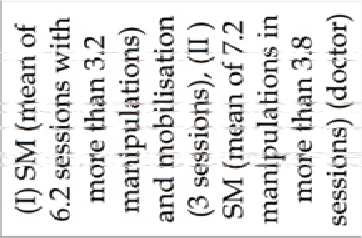 & 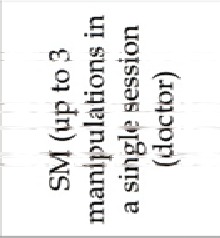 & 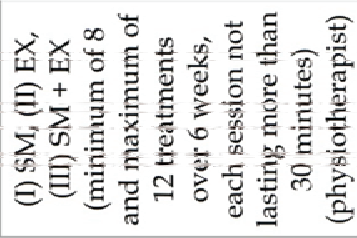 \\
\hline 总 & ॄ̃ & ڤั & 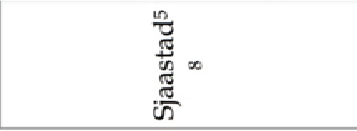 \\
\hline 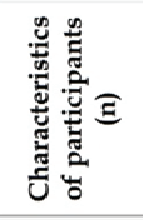 & 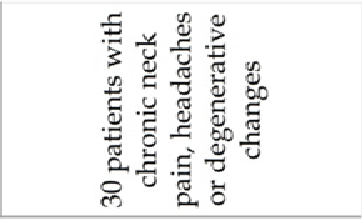 & 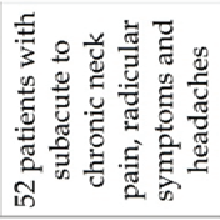 & 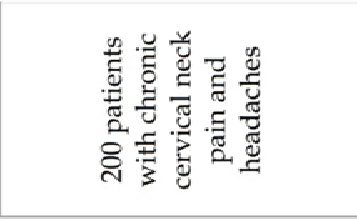 \\
\hline 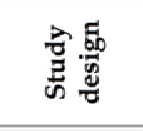 & 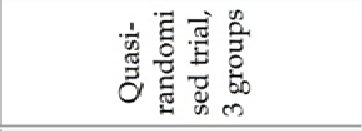 & 它主害 & 式言亮 \\
\hline 总 & 离尽 & 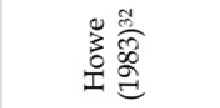 & 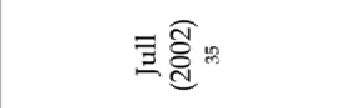 \\
\hline
\end{tabular}

$\mathrm{EX}=$ exercise $; \mathrm{RCT}=$ randomised clinical trial; $\mathrm{SM}=$ spinal manipulation, transcutaneous electrical nerve stimulation; VAS = visual analogue scale; - = inconclusive results.

Table 4. Spinal manipulation for the treatment of cervicogenic headaches in three of the included RCTs 


\begin{tabular}{|c|l|l|l|l|l|l|}
\hline $\begin{array}{c}\text { Author } \\
\text { (year) }\end{array}$ & $\begin{array}{c}\text { Random } \\
\text { sequence } \\
\text { generation }\end{array}$ & $\begin{array}{c}\text { Suitable } \\
\text { randomisation }\end{array}$ & $\begin{array}{c}\text { Blinding of } \\
\text { subjects or } \\
\text { personnel }\end{array}$ & $\begin{array}{c}\text { Blinding of } \\
\text { the outcome } \\
\text { reviewers }\end{array}$ & $\begin{array}{c}\text { Withdrawals } \\
\text { and } \\
\text { dropouts }\end{array}$ & $\begin{array}{c}\text { Total } \\
\text { (Jadad } \\
\text { score) }\end{array}$ \\
\hline $\begin{array}{c}\text { Bitterli } \\
(1977)^{34}\end{array}$ & 0 & 0 & 0 & 0 & 1 & 1 \\
\hline $\begin{array}{c}\text { Howe } \\
(1983)^{32}\end{array}$ & 1 & 0 & 0 & 0 & 0 & 1 \\
\hline $\begin{array}{c}\text { Jull } \\
(2002)^{35}\end{array}$ & 1 & 1 & 0 & 1 & 1 & 4 \\
\hline
\end{tabular}

Table 5. Quality Evaluation in three of the included RCTs (Jadad score) ${ }^{59}$

\begin{tabular}{|c|l|l|l|l|l|l|l|}
\hline $\begin{array}{c}\text { Author } \\
\text { (year) }\end{array}$ & $\begin{array}{c}\text { Sequence } \\
\text { generation }\end{array}$ & $\begin{array}{c}\text { Concealment } \\
\text { of allocation }\end{array}$ & $\begin{array}{c}\text { Blinding of } \\
\text { subjects, } \\
\text { personnel } \\
\text { or outcome } \\
\text { reviewers }\end{array}$ & $\begin{array}{c}\text { Incomplete } \\
\text { outcome } \\
\text { data }\end{array}$ & $\begin{array}{c}\text { Selective } \\
\text { outcome } \\
\text { reporting }\end{array}$ & $\begin{array}{c}\text { Other } \\
\text { sources } \\
\text { of bias }\end{array}$ & Total \\
\hline $\begin{array}{c}\text { Bitterli } \\
(1977) \\
34\end{array}$ & -1 & -1 & -1 & 0 & 0 & -1 & -4 \\
\hline $\begin{array}{c}\text { Howe } \\
(1983) \\
32\end{array}$ & 0 & -1 & -1 & -1 & -1 & -1 & -5 \\
\hline $\begin{array}{c}\text { Jull } \\
(2002) \\
35\end{array}$ & 1 & -1 & 1 & 1 & 1 & 0 & 3 \\
\hline
\end{tabular}

$>0=$ low risk of bias; $0=$ unclear risk of bias; $<0=$ high risk of bias.

Table 6. Quality Evaluation in three of the included RCTs (Cochrane tool) ${ }^{59}$

This review has some limitations. Although we used broad search criteria, we cannot guarantee that we did not miss any relevant publications. Due to the number of RTCs reviewed, the total number of subjects, and the low design quality, it is difficult to draw clear conclusions. Although the study populations in the RCTs are quite homogenous, it is not possible to perform a meta-analysis.

This overeview had the advantages of spanning the available literature on nonspecific cervical pain, included only the highest-quality studies, and used recommended methods for systematic reviews.

In the future, studies evaluating the efficacy and safety of manual therapy should be designed according to the international CONSORT recommendations. Furthermore, investigators need be very careful when performing sample size calculations in order to avoid sources of bias. 
The information in the studies should be sufficient to allow researchers to reproduce the results independently. The data could suggest a bias in favour of physiotherapists for the treatment of neck pain. However, this bias does not mean that physiotherapists are better qualified or that they are more effective in the application of cervical spinal manipulations compared with other healthcare professionals (see Tables 7, 8, and 9).

\begin{tabular}{|l|l|}
\hline $\begin{array}{l}\text { Author } \\
\text { (year) }\end{array}$ & Details of SM treatment (direct quote where applicable) \\
\hline $\begin{array}{l}\text { Bitterli } \\
(1977)^{34}\end{array}$ & $\begin{array}{l}\text { Patients in group B were treated by a doctor who was also a qualified massage } \\
\text { therapist. They received an average of } 7.2 \text { manipulations on the cervical spine } \\
\text { using the technique described by Maigne. }\end{array}$ \\
\hline \hline $\begin{array}{l}\text { Howe } \\
(1983)^{32}\end{array}$ & $\begin{array}{l}\text { The techniques are similar, with only small differences from those described by } \\
\text { Bourdillon. The essence of manipulation is to move the joint(s) as comfortably } \\
\text { as possible and then apply moderate, high-velocity but very low-amplitude } \\
\text { thrusts in the same direction. }\end{array}$ \\
\hline $\begin{array}{l}\text { Jull } \\
(2002)^{35}\end{array}$ & $\begin{array}{l}\text { Manipulative therapy (MT) described by Maitland. This therapy includes the } \\
\text { joint mobilisation technique (in which the segment is moved passively) and the } \\
\text { high-velocity technique. }\end{array}$ \\
\hline
\end{tabular}

Taking into account the variability and lack of standardisation of SM treatments, it is difficult to replicate these studies independently and/or draw firm conclusions.

Table 7. Details of spinal manipulation (SM) treatment in three of the included RCTs

\begin{tabular}{|l|l|}
\hline Author (year) & Details of adverse events \\
\hline Bitterli (1977) ${ }^{34}$ & $\begin{array}{l}\text { Manipulation and mobilisation were well tolerated, typically with a } \\
\text { minimal, mild reaction lasting less than 24 hours. }\end{array}$ \\
\hline Howe (198332 & NIP \\
\hline Jull (2002) & $\begin{array}{l}\text { Headache as a minor, transient side effect caused by treatment was } \\
\text { reported by 6.7\% of subjects during the 6-week intervention period. }\end{array}$ \\
\hline
\end{tabular}

$\mathrm{NIP}=$ no information provided. Two of the three RCTs reported adverse effects $(\mathrm{AE})^{[34,35]}$, and one RCT did not provide this information ${ }^{[32]}$.

Table 8. Adverse effects (AE) reported in three of the included RCTs

\begin{tabular}{|l|l|l|l|}
\hline $\begin{array}{l}\text { Author (year) } \\
\text { Profession }\end{array}$ & Positive & Negative & Inconclusive \\
\hline Howe $(1983)^{17} \mathrm{MD}$ & $=$ & - & - \\
\hline Bitterli $(1977)^{34} \mathrm{MD}$ & - & $=$ & - \\
\hline Jull $(2002)^{18} \mathrm{PT}$ & - & - & $=$ \\
\hline
\end{tabular}

$\mathrm{MD}=$ doctor of medicine; $\mathrm{PT}$ = physiotherapist - = inconclusive results.

Table 9. Positive versus negative studies by type of health professional in three of the included RCTs 


\section{Conclusions}

There is no evidence to support the use of spinal manipulations for acute neck pain, and there is limited evidence against passive spinal mobilisation. However, there is strong evidence against manipulation alone or manipulation in addition to mobilisation in isolation compared with control groups (placebo/waiting list) in terms of improving function and the general perceived effect for the treatment of subacute or chronic mechanical neck disorders with or without headache. There is strong short- and long-term evidence in favour of multimodal treatments (manipulation/mobilisation plus exercise) compared with control groups for reducing pain, thereby improving function and the general perceived effect in subacute or chronic mechanical neck disorders with or without headaches.

There is no evidence to support the role of manual therapy in cervical radicular conditions. There is evidence against the efficacy of isolated manipulation and/or mobilisation in the treatment of cervicogenic headaches. There were no serious adverse effects associated with the use of HVT techniques; a number of minor adverse effects were reported. The adverse effects associated with the use of non-HVT techniques were more serious and included a transient ischaemic attack, a fall due to this attack, and a fainting episode. The adverse effects associated with the use of non-HVT techniques justify a specific investigation, especially in view of their widespread use on the upper cervical spine.

There was a low utilisation of VBI assessment protocols, and the questionable utility of VBI assessment protocols in clinical practice was highlighted in one study. Positional VBI tests cannot detect all of the patients at risk of adverse effects associated with the use of manual therapy. Additional large-scale studies are needed to investigate the risk of serious adverse reactions associated with the use of both HVT and non-HVT techniques. Ideally, this research should not depend solely on subjective information obtained from providers, as was the case in this study. Finally, a notification system for adverse effects should be used on a routine basis. This system should incorporate protocols for collecting the adverse effects associated with the use of these techniques and the therapist's VBI assessment.

\section{References}

[1] Mirallas-Martínez JA. Cerebral vascular complications after cervical spinal manipulation. Rehabil (Madr) 2003; 37: 33-9.

[2] Gemmell H and Miller P. Comparative effectiveness of manipulation, mobilization and the activator instrument in treatment of nonspecific neck pain: A systematic review. Chirop \& Osteop 2006; 14: 1-7.

[3] Vastravers P, Maigne JY. Cervical manipulations and precautionary principles. Rev Rhum. (Ed. Fr) 2000; 67: 349-54

[4] Sackett DL, Straus SE, Richardson WS, Rosenberg W, Haynes RB. Evidence-Based Medicine: How to Practice and Teach EBM. Second Edition. Churchill Livingstone: Edinburgh 2000.

[5] Sarigiovannis P, Hollins B. Effectiveness of manual therapy in the treatment of nonspecific neck pain: A review. Phys Ther Rev 2005; 10: 35-50

[6] Koes BW, Assendelft WJ, van der Heijden GJ, Bouter LM, Knipschild PG. Spinal manipulation and mobilization for back and neck pain: A blinded review. BMJ 1991; 303:1,298-303 
[7] Aker PD, Gross AR, Goldsmith CH, Peloso P. Conservative management of mechanical neck pain: Systematic overview and meta-analysis. BMJ 1996; 313: 1,291-6.

[8] Hurwitz EL, Aker PD, Adams AH, Meeker WC, Shekelle PG. Manipulation and mobilization of the cervical spine: A systematic review of the literature. Spine 1997; 22: 1,676-7.

[9] Gross AR, Kay T, Hondras M, Goldsmith C, Haines T, Pelosos P, Kennedy C, Hoving J. Manual therapy for mechanical neck disorders: A systematic review. Man Ther 2002; 7:131-49

[10] Gross AR, Hoving JL, Haines TA, Goldsmith CH, Kay T, Aker P, Bronfort G, Cervical Overview Group. A Cochrane review of manipulation and mobilization for mechanical neck disorders. Spine 2004; 29:1,541-8.

[11] Ernst E. Chiropractic spinal manipulation for neck pain: A systematic review. J Pain 2003; 4: 417-21.

[12] Vernon H, Aker P, Burns S, Vijakaanen S, Short L. Pressure-pain threshold evaluation of the effect of spinal manipulation in the treatment of chronic neck pain: A pilot study. J Manip Physiol Ther 1990; 13:13-6.

[13] Wood TG, Colloca CJ, Matthews R. A pilot randomised clinical trial on the relative effect of instrumental (MFMA) versus manual (HVLA) manipulation in the treatment of cervical spine dysfunction. J Manipul Physiol Ther 2001;24:260-71.

[14] Pikula JR. The effect of spinal manipulative therapy (SMT) on pain reduction and range of motion in patients with acute unilateral neck pain: A pilot study. J Can Chiropractic Assoc 1999;43:111-9

[15] Parkin-Smith GF, Penter CS. A clinical trial investigating the effect of two manipulative approaches in the treatment of mechanical neck pain: A pilot study. J Neuromusculoskel System 1998;6: 6-16

[16] Moodley M, Brantingham JW. The relative effectiveness of spinal manipulation and ultrasound in mechanical pain: Pilot study. Chiropractic Technique 1999;11:164-8.

[17] Brodin H. Cervical pain and mobilization. Manual Med 1985;2:18-22.

[18] Jordan A, Bendix T, Nielsen H, Hansen FR, Host D, Winkel A. Intensive training, physiotherapy, or manipulation for patients with chronic neck pain: A prospective, single-blinded, randomised clinical trial. Spine 1998; 23: 311-9.

[19] Nordemar R, Thörner C. Treatment of acute cervical pain: A comparative group study. Pain 1981;10: 93-101.

[20] Hoving JL, Koes BW, de Vet HCW, van der Windt DAWM, Assendelft WJJ, van Mameren $\mathrm{H}$ et al: Manual therapy, physical therapy, or continued care by a general practitioner for patients with neck pain. A randomised, controlled trial. Ann Inter Med 2002;136:713-59.

[21] Hurwitz EL, Morgenstern H, Harber P, Kominski GF, Yu F, Adams AH. A randomised trial of chiropractic manipulation and mobilization for patients with neck pain: Clinical outcomes from the UCLA neck-pain study. Am J Public Health 2002; 92:1,634-41.

[22] Bronfort G, Evans R, Nelson B, Aker PD, Goldsmith CH, Vernon H. A randomised clinical trial of exercise and spinal manipulation for patients with chronic neck pain. Spine 2001; 26:788-99. 
[23] Evans R, Bronfort G, Nelson B, Goldsmith CH. Two-year follow-up of a randomised clinical trial of spinal manipulation and two types of exercise for patients with chronic neck pain. Spine 2002; 27: 2,383-9.

[24] Yurkiw D, Mior S. Comparison of two chiropractic techniques on pain and lateral lesion in neck pain patients: a pilot study. Chirop Tech 1996; 8: 155-62.

[25] Hurwitz EL, Aker PD, Adams AH, Meeker WC, Shekelle PG. Manipulation and mobilization of the cervical spine: a systematic review of the literature. Spine 1996; 21:1,746-60.

[26] Mealy K, Breman H, Fenelon GC. Early mobilization of acute whiplash injuries. BMJ 1986; 292: 656-7.

[27] McKinney LA. Early mobilization and outcome in acute sprain of the neck. BMJ 1989; 299:1,006-8.

[28] Koes BW, Bouter LM, van Mameren H, Esser AH, Verstegen GM, Hofhuizen DM, Houben JP, Knipschild PG. Randomized clinical trial of manipulative therapy and physiotherapy for persistent back and neck complaints: results of one year follow up. BMJ 1992; 304:601-5.

[29] Kay TM, Gross A, Santaguida PL, Hoving J, Goldsmith C, Bronfort G. Cervical Overview Group. Exercises for mechanical disorders of the neck. (translation of the Cochrane Revision). In The Cochrane Library Supplement, 2005, Number 1. Oxford: Update Software, Ltd. Available at: http//www.update-software.com (translation of The Cochrane Library, 2006, Issue 1. Chichester, UK: John Wiley \& Sons, Ltd.).

[30] Ylinen J, Takala E-P, Nykänen M, Häkkinen A, Mälkiä E, Pohjolainen T, Karppi SL, Kautiainen $\mathrm{H}$, Airaksinen: Active neck muscle training in the treatment of chronic neck pain in women. A randomized controlled trial. JAMA 2003; 289: 2,509-16.

[31] Cassidy JD, Lopes AA, Yong-Hing K. The immediate effect of manipulation versus mobilization on pain and range of motion in the cervical spine: a randomised controlled trial. J Manipulative Physiol Ther 1992; 15:570-5

[32] Howe DH, Newcombe RG, Wade MT. Manipulation of the cervical spine-a pilot study. J R Coll Gen Pract 1983; 33: 574-9.

[33] Sloop PR, Smith DS, Goldenberg E, Dore C. Manipulation for chronic neck pain: a double-blind controlled study. Spine 1982; 7: 532-5.

[34] Bitterly J, Graf R, Robert F, Adler R, Mumenthaler M. Evaluation of physical therapy for the control of spondylogenic headaches. Nervenarzt 1977; 48: 259-62.

[35] Jull G, Trott P, Potter H, Zito G, Niere K, Shirley D, et al: A randomized controlled trial of exercise and manipulative therapy for cervicogenic headache. Spine 2002, 27: 1,835-43.

[36] Karlberg M, Magnusson M, Eva-Maj M, Melander A, Moritz U. Postural and symptomatic improvement after physiotherapy in patients with dizziness of suspected cervical origin. Arch Phys Med Rehabil 1996; 77: 874-82.

[37] Allison GT, Nagy BM, Hall T. A randomized clinical trial of manual therapy for cervicobrachial pain syndrome - a pilot study. Man Ther 2002;7: 95-102

[38] Cagnie B, Vinck E, Beernaert A, Cambier D, How common are side effects of spinal manipulation and can these side effects be predicted?, Manual Therapy 2004; 9: 1516 
[39] Di Fabio RP. Manipulation of the cervical spine: risks and benefits, Physical Therapy 1999; 79: 50-65.

[40] Rothwell DM, S.J. Bondy and J.L. Williams, Chiropractic manipulation and stroke: a population-based case-control study. Stroke 2001; 32: 1,054-60.

[41] Ernst E. Adverse effects of spinal manipulation: A systematic review, Journal of the Royal Society of Medicine 2007; 100: 330-8.

[42] Haldeman S, Kohlbeck FJ, McGregor M. Unpredictability of cerebrovascular ischemia associated with cervical spine manipulation therapy: A review of sixty-four cases after cervical spine manipulation, Spine 2002; 27: 49-55.

[43] Michaeli A. Reported occurrence and nature of complications following manipulative physiotherapy in South Africa, Australian Journal of Physiotherapy 1993; 39: 309-15.

[44] Magarey ME, Rebbeck T, Coughlan B, Grimmer K, Rivett DA, Refshauge K. Premanipulative testing of the cervical spine review revision and new clinical guidelines. Manual Therapy 2004; 9: 95-108.

[45] Thiel HW, Bolton JE, Docherty S, Portlock JC. Safety of chiropractic manipulation of the cervical spine. Spine 2007; 2375-8.

[46] Kerry R, Taylor A,. Mitchell J,. McCarthy C. Cervical arterial dysfunction and manual therapy: a critical literature review to inform professional practice, Manual Therapy (2008), pp. 278-88.

[47] Stevinson C, Honan W, Cooke B, Ernst E. Neurological complications of cervical spine manipulation, Journal of the Royal Society of Medicine 2002; 94: 107-10.

[48] Thiel HW, Bolton JE, Docherty S, Portlock JC. Safety of chiropractic manipulation of the cervical spine, Spine 2007; 2,375-8.

[49] Hurwitz EL, Morgenstern H, Vassilaki M, Chiang LM. Frequency and clinical predictors of adverse reactions to chiropractic care in the UCLA neck pain study. Spine 2005; 30: 13, 1,477-84.

[50] Australian Physiotherapy Association, Clinical guidelines for assessing vertebrobasilar insufficiency in the management of cervical spine disorders http:/ / www.physiotherapy.asn.au (2006) [accessed 11.11.08].

[51] Richter R, Reinking M. How does evidence on the diagnostic accuracy of the vertebral artery test influence teaching of the test in a professional physical therapy education program? Physical Therapy 2004; 85: 589-99.

[52] Côté P, Kreitz BG, Cassidy JD and H. Thiel. The validity of the rotation-extension test as a clinical diagnostic procedure before manipulation of the neck: A secondary analysis. Journal of manipulation and physiological therapeutics 19 (1996), pp. 159-164.

[53] Rivett D, Reid D. Risk of stroke for cervical spine manipulation in New Zealand, New Zealand Journal of Physiotherapy 26 (1998), pp. 14-17.

[54] Haynes M, Milne N. Colour duplex sonographic findings in human vertebral arteries during cervical rotation. Journal of Clinical Ultrasound 2000; 29: 14-24.

[55] Mirallas-Martínez JA. Effectiveness of manual therapy (manipulations and mobilisations) on nonspecific cervical pain: Scientific evidence. Rehabilitation (Madr.) 2007; 41(2): 81-7.

[56] Sweeney A, Doody C. Manual therapy for the cervical spine and reported adverse effects: A survey of Irish Manipulative Physiotherapists. Manual Therapy. 2010); 15: (1), 32-6. 
[57] Ernst E, Canter PH. A systematic review of systematic reviews of spinal manipulation. JR Soc Med. 2006; 99: 192-6.

[58] Sjaastad O, Fredriksen TA, Pfaffenrath V. Cervicogenic headache: diagnostic criteria. The Cervicogenic Headache International Study Group. Headache. 1998; 38:442-445

[59] Jadad AR, Moore RA, Carroll D, et al. Assessing the quality of reports of randomized clinical trials: is blinding necessary? Control Clin Trials. 1996; 17:1-12. 


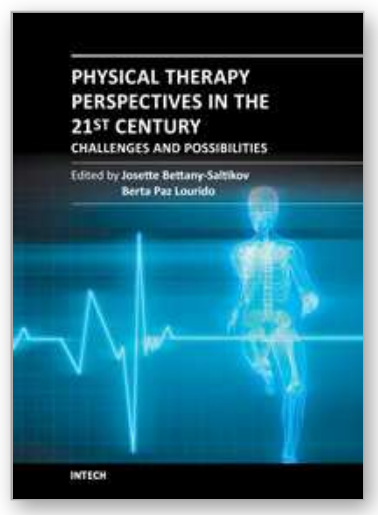

\section{Physical Therapy Perspectives in the 21st Century - Challenges and Possibilities}

Edited by Dr. Josette Bettany-Saltikov

ISBN 978-953-51-0459-9

Hard cover, 386 pages

Publisher InTech

Published online 05, April, 2012

Published in print edition April, 2012

This book contains new information on physical therapy research and clinical approaches that are being undertaken into numerous medical conditions; biomechanical and musculoskeletal conditions as well as the effects of psychological factors, body awareness and relaxation techniques; specific and specialist exercises for the treatment of scoliosis and spinal deformities in infants and adolescents; new thermal agents are being introduced and different types of physical therapy interventions are being introduced for the elderly both in the home and clinical setting. Additionally research into physical therapy interventions for patients with respiratory, cardiovascular disorders and stroke is being undertaken and new concepts of wheelchair design are being implemented.

\section{How to reference}

In order to correctly reference this scholarly work, feel free to copy and paste the following:

Jose Antonio Mirallas Martinez (2012). An Overview on the Efficacy of Manual Therapy (Manipulations and Mobilisations) on Nonspecific Cervical Pain:A Systematic Review in Adults, Physical Therapy Perspectives in the 21st Century - Challenges and Possibilities, Dr. Josette Bettany-Saltikov (Ed.), ISBN: 978-953-51-0459-9, InTech, Available from: http://www.intechopen.com/books/physical-therapy-perspectives-in-the-21st-centurychallenges-and-possibilities/an-overview-on-the-efficacy-of-manual-therapy-manipulations-and-mobilisationson-nonspecific-cervica

\section{INTECH}

open science | open minds

\section{InTech Europe}

University Campus STeP Ri

Slavka Krautzeka 83/A

51000 Rijeka, Croatia

Phone: +385 (51) 770447

Fax: +385 (51) 686166

www.intechopen.com

\section{InTech China}

Unit 405, Office Block, Hotel Equatorial Shanghai

No.65, Yan An Road (West), Shanghai, 200040, China

中国上海市延安西路65号上海国际贵都大饭店办公楼 405 单元

Phone: +86-21-62489820

Fax: $+86-21-62489821$ 
(C) 2012 The Author(s). Licensee IntechOpen. This is an open access article distributed under the terms of the Creative Commons Attribution 3.0 License, which permits unrestricted use, distribution, and reproduction in any medium, provided the original work is properly cited. 